\title{
ENCOURAGING STUDENTS TO HAVE POSITIVE ATTITUDES TOWARD LEARNING ENGLISH
}

\author{
Ismail Sangkala \\ English Education Department \\ Universitas Muhammadiyah Makassar
}

ismail@unismuh.ac.id

In foreign Language learning context, there are various factors that influence the learning process such as motivation, attitudes, anxiety, learning achievements, aptitudes, intelligence, age, personalities, etc. The matter of learner's attitude is acknowledged as one of the most important factors that impact on learning language. This study looks into the concept of attitude as one of the major affective factors for success in learning a foreign language.

Meanwhile, the controversial concern is why some EFL students attain higher grades in English language exams than others who are under the same conditions and situations. We can say that, attitude is determined by the individual's beliefs about outcomes or attributes of performing the behavior (behavioral beliefs), weighted by evaluations of those outcomes or attributes. Thus, a person who holds strong beliefs that positively valued outcomes will result from performing the behavior will have a positive attitude toward the behavior. Conversely, a person who holds strong beliefs that negatively valued outcomes will result from the behavior will have a negative attitude. 
And the importance of attitude is considered as an essential factor influencing language performance, Achievement in a target language relies not only on intellectual capacity, but also on the learner's attitudes towards language learning. This means that learning language should be approached primarily as a social and psychological phenomenon rather than as a purely academic one. So we have been concluded that the ability of the students to master a second language is not only influenced by the mental competence or, language skills, but also on the students' attitudes and perceptions towards the target language. They also advocated that attitude concept could enhance the process of language learning, influencing the nature of student's behaviors and beliefs towards the other language, its culture and community, and this will identify their tendency to acquire that language.

Accordingly, the attitude concept has three components i.e., behavioral, cognitive and affective. These three attitudinal aspects are based on the three theoretical approaches of behaviorism, cognitivism and humanism respectively. In the following, the three aspects of attitude concept i.e., behavioral, cognitive, and emotional aspects are briefly described.

The respondents' obvious negative attitude towards English may lead to conclude that they are not well aware of the importance of English and learn it as a compulsory subject. Briefly, attitude concept is considered as an essential component in language learning. So, a positive attitude 
should be the umbrella of language learning. EFL teachers should respect and think about students' feelings, beliefs and behaviors before the cognitive abilities. English curriculum and classroom activities should involve affective aims according to the students' needs and their individual differences to build up positive attitudes towards English. It is so important to study learners' personalities. Cognitive performance can be achieved if the EFL learners possess positive attitudes and enjoy acquiring the target language. For that reason, the affective perspective, especially attitude, should be considered in language research.

\section{Reference}

Baker, C. (1992). Attitudes and Language. Clevedon, England: Multilingual Matters. 